\title{
Ghana y Guatemala: Clientas y proveedores requieren de apoyo y orientación sobre DIU
}

Frontiers in Reproductive Health

Follow this and additional works at: https://knowledgecommons.popcouncil.org/departments_sbsr-rh How does access to this work benefit you? Let us know!

\section{Recommended Citation}

"Ghana y Guatemala: Clientas y proveedores requieren de apoyo y orientación sobre DIU," FRONTERAS Resumen de Investigación Operativa. Ciudad de México: Population Council, 2003. 
Ghana y

Guatemala

Opciones

anticonceptivas

Investigación
operativa

Resumen 21

\section{Clientas y proveedores requieren mayor apoyo y orientación sobre el DIU}

\author{
La falta de conocimientos de proveedores y clientas, así como problemas \\ logísticos y lineamientos complicados, han contribuido a que la tasa de uso \\ del DIU en Ghana y Guatemala sea baja. Los esfuerzos para aumentar su \\ uso deben incluir la capacitación integral de los proveedores, una mayor \\ educación para las clientas y apoyo logístico.
}

\section{Antecedentes}

El dispositivo intrauterino (DIU), o T de Cobre 380A, es un método anticonceptivo seguro, efectivo, de largo plazo y reversible; es apropiado para las mujeres que no quieren embarazarse pronto y ofrece protección hasta por diez años. Sin embargo, en muchos países su uso está estancado o ha declinado en relación con otros métodos anticonceptivos. En el año 2002, el Population Council investigó las razones de la baja utilización del DIU en Guatemala y Ghana.

Ambos estudios examinaron el conocimiento y actitudes de clientas y proveedores al respecto, así como los factores dentro del sistema de salud que afectan su uso y disponibilidad.

Métodos elegidos por aceptantes de planificación familiar en clínicas de salud del gobierno, 2001

\begin{tabular}{lcc} 
Anticonceptivo & Ghana (\%) & Guatemala (\%) \\
Inyectable & 54.7 & 67.0 \\
\hline Oral & 25.3 & 12.9 \\
\hline Condón & 11.1 & 9.6 \\
\hline DIU & 1.9 & 3.1
\end{tabular}

Fuentes: Informe anual del servicio de salud de Ghana 2001 y Estadísticas de servicio del MSPAS de Guatemala, 2001

Los dos estudios se realizaron en clínicas y centros de salud públicos, privados y no gubernamentales, tanto en el ámbito urbano como en el rural. En ambos países, los investigadores obtuvieron información cualitativa por medio de una combinación de grupos focales, entrevistas a profundidad con proveedores y visitas de clientas simuladas, quienes representaron perfiles de mujeres con intención de espaciar o limitar sus embarazos. Los estudios incluyeron también un análisis secundario de las estadísticas de servicio para explorar las tendencias en el uso del DIU en ambos países, tanto en clínicas privadas como de gobierno.

\section{Hallazgos}

Entre los proveedores y las clientas, así como al interior de los sistemas de salud, numerosos factores contribuyeron a la baja demanda del DIU:

- Los conocimientos y habilidades de los proveedores eran inadecuados en ambos países. En Guatemala, a pesar de que la mayoría de los proveedores entrevistados habían recibido capacitación en la inserción y retiro del DIU, más de la mitad tenían información incorrecta acerca de sus efectos secundarios; casi una tercera parte tenían información equivocada sobre cuándo no es recomendable el uso del DIU. En Ghana, menos de una cuarta parte de los proveedores habían recibido capacitación sobre el DIU. En ambos estudios, debido a la baja demanda del método (sólo una o dos inserciones por mes en algunos lugares), los proveedores dijeron sentirse inseguros para mantener las habilidades clínicas recientemente adquiridas.

- El miedo y las percepciones equivocadas han limitado la demanda del DIU entre las clientas de planificación familiar. En los dos países, las mujeres mencionaron efectos secundarios legítimos, como cólicos y sangrados, como razones por las cuales no utilizar este método. Sin embargo, muchas tienen conceptos equivocados sobre el DIU y sus efectos secundarios: creen que provoca problemas con la pareja, infertilidad, hemorragias e incluso la muerte. También expresaron preocupación acerca de cómo un objeto como el DIU podía introducirse en el cuerpo. 
- Con frecuencia, la consejería sobre el DIU fue inadecuada. En Guatemala, menos de la mitad (41\%) de los prestadores de servicios ofrecieron información sobre el DIU a las clientas simuladas interesadas en espaciar sus embarazos. En Ghana, aproximadamente tres cuartas partes de las interacciones entre la clienta y el proveedor incluyeron consejería sobre el DIU, pero pocos proveedores comentaron acerca del DIU en el contexto del VIH/SIDA.

\section{"La llegada del SIDA dificulta el uso del DIU, ya que sólo previene el embarazo y no la enfermedad." -Proveedor, Ghana}

Los requisitos para la prestación del servicio limitan la disponibilidad del DIU. Para ofrecer los servicios de DIU, los establecimientos necesitan contar con personal capacitado, un área privada para realizar la exploración, equipo adecuado y suministros. En Guatemala, cerca del 90 por ciento de las clínicas y centros de salud del gobierno contaban con la infraestructura necesaria y al menos con un empleado capacitado en la inserción y retiro del DIU, pero cerca de la mitad carecían de suministros y equipo para ofrecer el servicio. En Ghana ocurría lo contrario: sólo el 56 por ciento de los establecimientos tenían la infraestructura necesaria para ofrecer el DIU, pero el 91 por ciento tenían los suministros necesarios disponibles.

- Los procedimientos y protocolos clínicos limitan el acceso. En Guatemala, las participantes de los grupos focales dijeron que el DIU resulta muy costoso porque deben trasladarse a una clínica urbana para obtenerlo. En Ghana, las políticas sólo permiten que las parteras coloquen el DIU, lo cual también restringe el acceso.
Las preferencias de las clientas están cambiando. El análisis de los registros de servicio muestra que la mayoría de las usuarias de planificación familiar en ambos países prefieren el inyectable DMPA. Los proveedores en Ghana también informaron que el miedo al VIH/SIDA ha incrementado el uso del condón como protección contra infecciones de transmisión sexual.

\section{Implicaciones normativas}

- Las clínicas que dan servicio a poblaciones que pueden mantener una demanda adecuada necesitan tener proveedores capacitados en consejería y en inserción y retiro del DIU. Es importante que los proveedores no sólo cuenten con el equipo y suministros necesarios, sino también con una tasa de inserciones mensuales suficiente para mantener las habilidades adquiridas.

Para disipar rumores y desmitificar el método, los mensajes sobre el DIU deben enfatizar tanto los atributos positivos del producto como sus contraindicaciones, $\mathrm{y}$ aclarar la información equivocada que se ha identificado.

Los lineamientos clínicos deben revisarse para incorporar la capacitación del personal paramédico, incluyendo a las auxiliares de enfermería, con el fin de incrementar el acceso al DIU en el ámbito rural.

- Durante la consejería, se debe informar a las clientas que el DIU es un método muy efectivo y conveniente para las parejas monógamas y que puede combinarse con el condón cuando la mujer no está segura de la situación de su(s) pareja(s) respecto a ITS y VIH-SIDA. Esta doble protección es recomendada por la OMS para las mujeres con VIH, para quienes un embarazo resultaría muy riesgoso.

\section{Fuentes:}

Gyapong, John, Gifty Addico, Ivy Osei, Mercy Abbey, Dominic Atweam Kobinah, Henrietta Odoi Agyarko, Gloria Quansah Asare, Harriet Birungi e Ian Askew. 2003. "An assessment of trends in the use of the IUD in Ghana [Análisis de las tendencias en el uso del DIU en Gana]," FRONTIERS Final Report. Washington, DC: Population Council. Disponible en nuestro portal: http://www.popcouncil.org/pdfs/frontiers/FR FinalReports/Ghana IUD.pdf o por correo electrónico: frontiers@pcdc.org

Brambila, Carlos y Berta Taracena. 2003. "Availability and Acceptability of IUDs in Guatemala [Disponibilidad y aceptación del DIU en Guatemala]," FRONTIERS Final Report. Washington, DC: Population Council. Disponible en nuestro portal: http://www.popcouncil.org/pdfs/frontiers/FR FinalReports/Guatemala IUD.pdf o por correo electrónico: frontiers@pcdc.org

Este proyecto se llevó a cabo con el apoyo de la AGENCIA DE LOS ESTADOS UNIDOS PARA EL DESARROLLO INTERNACIONAL (USAID) bajo el Acuerdo de Cooperación No. HRN-A-00-98-00012-00. 